NASA Technical Memorandum 106827

AIAA-95-0540

\title{
Methods for Scaling Icing Test Conditions
}

David N. Anderson

Lewis Research Center

Cleveland, Ohio

(NASA-TM-106827) METHOOS FOR
SCALING ICING TFST CONDITIONS
(NASA. LewiS RESEarCh Center) $11 \mathrm{p}$

$63 / 030035008$

Prepared for the

33rd Aerospace Sciences Meeting and Exhibit

sponsored by the American Institute of Aeronautics and Astronautics

Reno, Nevada, January 9-12, 1995

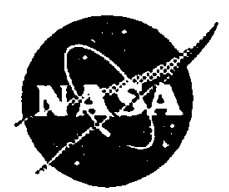

National Aeronautics and

Space Administration 


\author{
David N. Anderson \\ NASA Lewis Research Center \\ Cleveland, $\mathrm{OH}$
}

\begin{abstract}
This report presents the results of tests at NASA Lewis to evaluate several methods to establish suitable altemative test conditions when the test facility limits the model size or operating conditions. The first method was proposed by Olsen. It can be applied when full-size models are tested and all the desired test conditions except liquid-water content can be obtained in the facility. The other two methods discussed are: a modification of the French scaling law and the AEDC scaling method. Icing tests were made with cylinders at both reference and scaled conditions representing mixed and glaze ice in the NASA Lewis Icing Research Tunnel. Reference and scale ice shapes were compared to evaluate each method. The Olsen method was tested with liquid-water content varying from 1.3 to $.8 \mathrm{~g} / \mathrm{m}^{3}$. Over this range, ice shapes produced using the Olsen method were unchanged The modified French and AEDC methods produced scaled ice shapes which approximated the reference shapes when model size was reduced to half the reference size for the glaze-ice cases tested.
\end{abstract}

\section{Nomenclature}

$A_{c} \quad$ Accumulation parameter, dimensionless

$b$ Relative heat factor, dimensionless

c Characteristic model length, $\mathrm{cm}$

cp Specific heat, $\mathrm{cal} / \mathrm{gm} \mathrm{K}$

$h_{c}$ Convective film heat-transfer coefficient, $\mathrm{cal} / \mathrm{sec} \mathrm{m}^{2} \mathrm{~K}$

$k \quad$ Thermal conductivity, $\mathrm{cal} / \mathrm{sec} \mathrm{m} \mathrm{K}$

$K \quad$ Langmuir's Inertia Parameter, dimensionless

$K_{0} \quad$ Modified Inertia Parameter, dimensionless

LWC Liquid-water content, $g / \mathrm{m}^{3}$

$n \quad$ Freezing fraction, dimensionless

$\mathrm{Nu} \quad$ Nusselt number, dimensionless

$p \quad$ Ambient static pressure, $\mathrm{nt} / \mathrm{m}^{2}$

$R_{a} \quad$ Gas constant for air, $287.0 \mathrm{nt} \mathrm{m} / \mathrm{kg} \mathrm{K}$

$p_{\mathrm{w}} \quad$ Vapor pressure of water, $\mathrm{nt} / \mathrm{m}^{2}$

Re Reynolds number based on model size, dimensionless

$\operatorname{Re}_{\delta} \quad$ Reynolds number based on droplet diameter, dimensionless

Sc Schmidt number, dimensionless

$t \quad$ Ambient static temperature, ${ }^{\circ} \mathrm{C}$

$T$ Ambient static temperature, $\mathrm{K}$

$V \quad$ Airspeed, $\mathrm{m} / \mathrm{s}$

$\beta_{0} \quad$ Collection efficiency at leading edge, dimensionless

$\delta \quad$ Droplet median volume diameter, $\mathrm{mm}$

$\phi \quad$ Droplet-energy transfer term in energy equation, $\mathrm{K}$

$\theta \quad$ Air-energy transfer term in energy equation, $K$

$\lambda$ Droplet range, $\mathrm{m}$ $\lambda_{\text {Stokes }}$ Droplet range if Stokes law applies to drag, $m$

1 Latent heat of freezing, $\mathrm{cal} / \mathrm{gm}$

A. Latent heat of vaporization, $\mathrm{cal} / \mathrm{gm}$

$\mu \quad$ Viscosity, $g \mathrm{~m} / \mathrm{cm}$ s

$\rho$ Density, dyne/ $\mathrm{cm}^{3}$

$\tau \quad$ Icing time, min

Subscripts:

$\begin{array}{ll}a & \text { Air } \\ i & \text { Ice } \\ R & \text { Reference size and conditions } \\ \text { surf } & \text { Surface } \\ S & \text { Scale size and conditions } \\ \text { tot } & \text { total } \\ w & \text { Water }\end{array}$

\section{Introduction}

In wind tunnel testing the researcher is often faced with facility limitations which prevent testing at desired conditions. In addition, the test article must normally be reduced in size relative to the device of interest. Therefore reliable techniques are needed to permit the scaling of test conditions in such a way that an experimental ice shape adequately represents that which would accrete on the reference (full-size) hardware at the required airspeed and cloud conditions. In an effort to extend the usefulness of the NASA Lewis Icing Research Tunnel (IRT), studies have been carried out for several years to evaluate various scaling methods. Reference 1 showed that a number of published scaling laws adequately scale for rime ice but not for mixed or glaze. Rime ice results from immediate freezing of water that impacts the model; therefore, heat-transfer considerations are not important and only the droplet trajectory and water accumulation need to be matched between reference and scale conditions to produce properly scaled ice shapes. For mixed and glaze ice, however, heat-transfer at the leading edge must be included in the scaling analysis. The poor agreement of the ice-shapes for reference and scale conditions reported in reference 1 was attributed in part to problems with the heat transfer analysis.

This report presents the results of tests of three methods not discussed in reference 1. The first is the Olsen method ${ }^{2}$, a modification of the often-used rule, LWC $x$ time $=$ constant. In the Olsen method, in addition to keeping the water catch constant between scale and reference situations, the scale and reference freezing fractions are also matched. The second is a modification of the French scaling method presented by Charpin and Fasso ${ }^{3}$. Charpin and Fasso's original analysis included a convective beattransfer coefficient applicable to turbulent flow $\left(N u \propto R e^{.8}\right)$. It was speculated in reference 1 that scaled ice shapes might match reference shapes better if a laminar-flow form $\left(\mathrm{Nu} \propto R e^{5}\right)$ of the 
convective heat-transfer coefficient were used. This modification was made to the French method as it was tested in this study. Finally, the AEDC method ${ }^{4}$ was tested; it had not been included in the study of reference 1. This method, like the French, matches droplet trajectories, accumulation parameter and several of the terms in the heat balance between scale and reference situations. The heat balance analysis incorporates a laminar-flow form of the convective film coefficient.

Tests were conducted with cylinders of different diameters in the Lewis Icing Research Tunnel (IRT). Several sets of reference conditions were first chosen along with a scale size and airspeed. For the Olsen method, the scale size and airspeed were matched to their respective reference values. The other two methods permit the model size to be scaled, and test airspeeds were chosen to be the same or less than the reference. Each method being evaluated was used to determine the remaining scaled conditions which corresponded with each set of reference conditions. Tests were run with both reference and scale conditions for each test case, and the ice shapes were recorded and compared. Reference conditions included cylinder diameters of 15.6 and $5.1 \mathrm{~cm}$ (6 and 2 in), total temperatures of -7.8 to $-2.1^{\circ} \mathrm{C}\left(18\right.$ to $\left.28^{\circ} \mathrm{F}\right)$, airspeeds of 76 to 94 $\mathrm{m} / \mathrm{s}(170$ to $210 \mathrm{mph})$, median volume droplet diameters of 28 to $30 \mu \mathrm{m}$, liquid-water contents of .6 to $1.3 \mathrm{~g} / \mathrm{m} 3$, and spray times of 7.8 to $19.1 \mathrm{~min}$. To test the Olsen method, $L W C$ was varied from .8 to $1.3 \mathrm{~g} / \mathrm{m}^{3}$. Scaled tests of the modified French and AEDC methods were made with 2.5 -cm-diameter cylinders and with scaled airspeeds of 61 to $94 \mathrm{~m} / \mathrm{s}$.

\section{Description of Experiment}

NASA Lewis Icing Research Tunnel. The experiments were performed in the NASA Lewis Icing Research Tunnel ${ }^{5}$ (IRT) shown in figure 1 . The IRT has a test section width of $2.74 \mathrm{~m}$ (9 ft) and a height of $1.83 \mathrm{~m}(6 \mathrm{ft}$ ) It is capable of operation at test-section velocities up to $160 \mathrm{~m} / \mathrm{s}(350 \mathrm{mph}$ ). A refrigeration system permits accurate control of the test-section temperature from -40 to $5^{\circ} \mathrm{C}\left(-40\right.$ to $40^{\circ} \mathrm{F}$.) A water-spray system ${ }^{6}$ with 8 spray bars provides the ability to control test-section liquid-water content from .2 to $3 \mathrm{~g} / \mathrm{m} 3$ and droplet median volume diameters from 15 to $40 \mu \mathrm{m}$.

Two sets of spray nozzles, known as the mod-1 and standard nozzles, are used in the IRT to provide different ranges of liquid-water content and droplet size ${ }^{6}$.

Scaling Test Hardware. Ice accretion was measured on hollow circular ahumimum cylinders. Each cylinder was mounted vertically in the center of the test section. Cylinders with 15.2-, 5.1- and 2.5-cm (6-, 2- and 1-in) diameters were used. Figure 2 shows how the test cylinders were mounted in the IRT test section. A retractable shield protected the test cylinder from ice during the waler spray bar start-up transient. Figure 2 shows this shield in the retracted position; phantom lines indicate its location when lowered to protect the cylinder from the initial spray.

Test Procedure. Tests were performed by first establishing the tumel airspeed and temperature. Water spray conditions were then selected, and when tumnel conditions had stabilized, the water spray was initiated. The spray-bar conditions typically stabilized after about 1 minute. When the spray-bar air and water pressures reached steady values, the shield shown in figure 2 was raised to expose the cylinder, and the spray timer was started. When the prescribed spray period was completed, the spray was shut off and the tunnel brought to idle to permit personnel entry into the test section. The ice shape was then recorded, the model was cleaned and the procecture repeated for the next spray condition.

The ice shape was recorded manually for each test. A heated aluminum block with a semicircular cut-out of the appropriate diameter was used to melt a slice into the ice normal to the cylinder axis at the test-section centerline. A cardboard template, also with a semicircular cut-out to match the cylinder diameter, was placed in the resulting gap in the ice, and the ice shape was traced onto the cardboard template. The tracing was later digitized for computer storage of the information.

\section{Scaling Methods Tested}

Three scaling methods were tested: a method devised by Olsen ${ }^{2}$ for correcting for $L W C$ changes, a modified version of the French scaling law described in reference 3, and the AEDC scaling approach ${ }^{4}$. Each of these methods will be described here.

In the following discussion the term reference is applied to the conditions and ice shape to be simulated while the simulation (sometimes with reduced size and sometimes with altered test conditions) is termod scale. The subscript $R$ will be used for reference conditions and model size, while the subscript $S$ will be used to indicate scale conditions and size.

Olsen Method The approach suggested by $\mathrm{Olsen}^{2}$ was a modification of the familiar rule,

$$
L W C_{S^{\tau}} S^{=L W C} R_{R}^{\tau}
$$

Equation (1) follows from matching the scale and reference accumulation parameters, where the accumulation parameter is

$$
A_{c}=\frac{L W C V_{\tau}}{c p_{t}}
$$

Equation (1) is valid only if the scale model size matches the reference size and if none of the test conditions, except the scale $L W C$, differs from the reference value. Thus, the equations applicable to the use of $L W C \times$ time = constant are:

$$
c_{s}=c_{R}
$$




$$
\begin{gathered}
\delta_{S}=\delta_{R} \\
V_{S}=V_{R} \\
L W C_{S}=[\text { edected byweed] } \\
\tau_{S}=\tau_{R} \frac{L W C_{R}}{L W C_{S}} \\
t_{S}=t_{R}
\end{gathered}
$$

Equations (3) - (8) constitute the $L W C \times$ time = constant law. With the exception of equation (8), they are also the basis of the Olsen scaling method. However, equation (8) overly simplifies the heat balance at the leading edge of the model. It is only valid for rime conditions where heat transfer does not affect the ice shape, or for situations in which there is little difference between the scale and reference $L W C$. For mixed-or glaze-ice conditions with significant differences between scale and reference $L W C$, reference 1 showed that this scaling law does not accurately reproduce the horn angle because of the effect of the liquid-water content on the leadingedge heat balance.

To account for the $L W C$ effects, the Olsen analysis requires that the scale and reference freezing fraction be equal. Messinger ${ }^{7}$ defined the freezing fraction as that fraction of water which freezes in the area of impact. From the Messinger energy equation, the freezing fraction can be expressed as

$$
n=\frac{c_{p, w}}{\Lambda_{f}}\left(\phi+\theta \frac{h_{c}}{L W C V \beta_{0} c_{p, w}}\right)
$$

where $\phi$ represents the transfer of droplet energy to the surface,

$$
\phi=t_{f}-t-\frac{V^{2}}{2 c_{p, w}}
$$

and $\theta$ represents the transfer of energy from the air to the surface:

$$
\theta=t_{\text {enff }}-t-r \frac{V^{2}}{2 c_{p, \varepsilon}}+.693 \frac{\mathrm{gm} \mathrm{K}}{\text { joule }} \Lambda_{v} \frac{P_{\text {weng }}-P_{w}}{P}
$$

In equation (11), $r$ is the recovery factor, taken as .875 in this study, and the factor $.693 \mathrm{gm} \mathrm{K} /$ joule is the ratio of the evaporative to the convective heat transfer coefficient.
The convective heat-transfer coefficient for the leading edge of an airfoil or cylinder which Olsen used in equation (9) is

$$
h_{c}=1.05 \frac{k}{c} R_{e} s
$$

The collection efficiency, $\beta_{a}$ in equation (9) can be found from the method of Langmuir and Blodgett ${ }^{8}$ which follows. Langmuir and Blodgett gave for cylinders:

$$
\beta_{0}=\frac{1.4\left(K_{0}-.125\right)^{.4}}{1+1.4\left(K_{0}-.125\right)^{.4}}
$$

where $K_{0}$ was defined as

$$
K_{0}=\frac{\lambda}{\lambda_{\text {suts }}}(K-.125)+.125
$$

In equation (14), $\lambda / \lambda_{\text {stokes }}$ is Langmuir and Blodgett's range parameter, defined as the ratio of the actual range of a droplet acted upon by the drag of the airflow divided by the range if the drag were determined by Stokes law. This parameter is a function of $R e_{\delta}$ It was tabulated by Langmuir and Blodgett; for this study the following fit to their tabulation was used:

$$
\begin{gathered}
\frac{\lambda}{\lambda_{\text {seates }}}= \\
\frac{.920-.132 \ln \left(R_{8}\right)+.00445 \ln \left(R_{8}\right)^{2}}{1-.0762 \ln \left(R_{e_{8}}\right)+.0198 \ln \left(R_{8}\right)^{2}+.000753 \ln \left(R_{8}\right)^{3}}
\end{gathered}
$$

$K$ in equation (14) is the inertia parameter

$$
K=\frac{\rho_{w} \delta^{2} V}{18 \mu_{e} c}
$$

When $n_{S}$ is equated with $n_{R}$ the following expression results for the scale temperature:

$$
t_{S}=t_{R}+\frac{h_{c}}{V \beta_{0} c_{p, W}}\left(\frac{\theta_{S}}{L W C_{S}}-\frac{\theta_{R}}{L W C_{R}}\right)
$$

Equation (17) must be solved iteratively for temperature since $\theta_{S}$ is itself a function of temperature (see equation (11)). Equations (3) - (7) and (17) make up the Olsen method. Although it is less convenient than the $L W C \times$ time = constant method, the greater rigor of the analysis should provide improved reproduction of ice 
shapes when $L W C$ is varied.

Modified French Scaling Method The original French scaling law was published by Charpin and Fasso ${ }^{3}$. This method can be applied to situations for which the scale size does not necessarily match the reference. In addition, a convenient scale airspeed may be chosen sccording to the capabilities of the test facility, it need not equal the reference airspeed. This law was tested in reference 1 where it was noted that the form of the convective heat transfer coefficient used in the Charpin and Fasso analysis was appropriate to turbulent flow. The ice shapes from tests scaled using the French method in the IRT did not always match the reference shapes in that study, and the form of the discrepancy suggested that better results might be achieved if a laminar-flow film coefficient were used in the analysis. With this modification to the French method, the following equations can be used to determine scaling test conditions:

$$
\begin{aligned}
& c_{s}=\text { [selected byuser ] } \\
& V_{s}=\text { [selected byuser] }
\end{aligned}
$$

The scale static pressure can be found from the total pressure for the test facility:

$$
P_{s}=P_{\text {toxss }}\left(1-\frac{V_{s}^{2}}{2 R_{s} T_{s}}\right)
$$

It can be shown (see, for example, Rufft) that when the droplet equation of motion for the scale and reference situations are equated, the scale droplet size can be found from the following approximate expression:

$$
\delta_{S}=8_{R}\left(\frac{c_{S}}{c_{R}}\right)^{.62}\left(\frac{p_{S}}{P_{R}}\right)^{.24}\left(\frac{v_{S}}{V_{R}}\right)^{-38}
$$

The relative heat factor was defined by Tribus $^{9}$ as

$$
b=\frac{L W C V \beta_{0} c_{p, W}}{h_{c}}
$$

The French method equates $b_{S}$ with $b_{R}$ and the scale and reference collection efficiencies, $\beta_{0}$ are also matched. $\beta_{0}$ can be found from equation (13). For the convective film coefficient, the original French method used

$$
h_{c} \propto \frac{k_{e}}{c} R e \cdot
$$

For the modified French method, $h_{c}$ is taken from equation (12) instead of equation (23). When equation (12) is substituted into equation (22) and the scale and reference relative heat factors equated, the scale liquid-water content can be found:

$$
\operatorname{LFC}_{s}=\operatorname{LWC}_{R}\left(\frac{P_{s}}{P_{R}}\right)^{s}\left(\frac{c_{s}}{c_{R}}\right)^{s}\left(\frac{V_{s}}{V_{R}}\right)^{-s}
$$

This equation is the only one that differs from the equations published in Charpin and Fasso ${ }^{3}$ describing the original French method.

Once the $L W C_{S}$ is known, the scale encounter time can be determined from equation (2):

$$
\tau_{s}=\tau_{R} \frac{c_{s}}{c_{R}} \frac{V_{R}}{V_{s}} \frac{L W C_{R}}{L W C_{s}}
$$

Finally, the scale static temperature is found by setting the scale and reference freesing fractions (see equation (9)) in the Messinger energy equation equal. The equation that results is ${ }^{3}$

$$
\begin{gathered}
t_{g}=t_{R}+\frac{1.058 \times 10^{6} \mathrm{Knt} / \mathrm{m}^{2}}{1+b}\left(\frac{1}{P_{S}}-\frac{1}{P_{R}}\right)- \\
\frac{1732 \mathrm{~K}}{1+b}\left(\frac{P_{w S}}{P_{S}}-\frac{P_{w R}}{P_{R}}\right)-\frac{(3.646+b)\left(V_{S}^{2}-V_{R}^{3}\right)}{(1+b) 8373 \mathrm{~m}^{2} / \mathrm{s}^{2} \mathrm{~K}}
\end{gathered}
$$

The vapor pressures, $p_{w, S}$ and $p_{w, R}$ are those corresponding with the temperatures $t_{S}$ and $t_{R}$. Thus, equation (26) must be solved iteratively for the scale temperature, $t_{s}$. The vapor pressures for this study were taken from reference 10 .

Although equation (26) is identical to that in the original French analysis, the static temperatures it gives for the French and modified French methods will not be the same because the relative heat factor found from equation (22) will differ for the two analyses. In practice, the difference in temperatures is small, however, and the main distinction between the scale results from the two methods will be the value of the liquid-water content.

AEDC The AEDC scaling analysis ${ }^{4}$ is similar to that of Charpin and Fasso in that both match scale and reference droplet trajectories, accumulation parameters and heat balance analyses. However, the expressions used to evaluate some of the parameters are different, different terms in the heat-balance analysis are matched and solution techniques are not always the same. Thus, 
the resulting scale test conditions for the two methods vary somewhat. The full set of equations used to determine scale conditions from given reference conditions is given here.

As with the French and modified French methods, the user of the AEDC method can choose scale size and airspeed:

$$
\begin{aligned}
& \left.c_{s}=\text { [selected byuser }\right] \\
& v_{s}=[\text { selected by user }]
\end{aligned}
$$

When scale and reference droplet energy transfer terms (see equation (10)) in the Messinger ${ }^{7}$ equation are matched, the static scale temperature can be found:

$$
t_{s}=t_{R}+\frac{V_{R}^{2}}{2 c_{p, w}}-\frac{V_{S}^{2}}{2 c_{p, w}}
$$

As with the French method, the scale static pressure is found from the total pressure for the test facility:

$$
P_{S}=P_{\text {cocs } S}\left(1-\frac{v_{S}^{2}}{2 R_{e} T_{S}}\right)
$$

The droplet size is found by matching the particle trajectories. Ruff did this by matching the modified inertia parameter, $K_{0}$ :

$$
\boldsymbol{K}_{0, s}=\boldsymbol{K}_{0, R}
$$

Where $K_{0}$ was defined by equation (14) in the discussion of the Olsen method. The scale drop size, $\delta_{S}$ is found by solving equation (31), using equations (14) - (16), iteratively.

The freezing fraction, $n$, was defined by equation (9). The scale liquid-water content, $L W C_{S}$ can now be determined by equating $n_{S}$ with $n_{R}$. Since the droplet energy terms are matched in Ruff's $\operatorname{method}\left(\phi_{S}=\phi_{R}\right.$ was the basis of equation (29)) and the collection efficiency, $\beta_{0}$, must also match,

$$
L W C_{S}=L W C_{R} \frac{\theta_{S}}{\theta_{R}} \frac{h_{C S}}{h_{C R}} \frac{V_{R}}{V_{S}}
$$

Here Ruff used the convective heat transfer coefficient from Kreith ${ }^{11}$

$$
h_{c}=\frac{1.14 \operatorname{Re}^{5} \operatorname{Pr}^{4} k_{e}}{c}
$$

The $\theta \mathrm{s}$ in equation (32) are the scale and reference air energy transfer terms, where $\theta$ was given by Ruff as

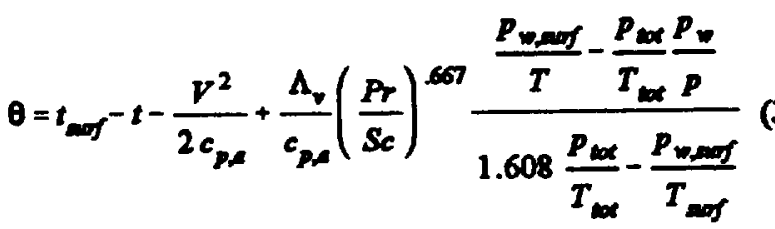

$p_{w, \text { sur }}$ is the vapor pressure at the surface temperature, $t_{\text {suff }} t_{\text {surf }}$ $=0^{\circ} \mathrm{C}$ was used in this study. The vapor pressures were taken from reference 10 .

To insure that the total amount of ice accreted for the scale situation matches the reference accretion, the accumulation parameter, $A_{c}$, (equation (2)) must match. Thus, the scale icing exposure time is

$$
\tau_{S}=\tau_{R} \frac{c_{S}}{c_{R}} \frac{L W C_{R}}{L W C_{S}} \frac{V_{R}}{V_{S}}
$$

The complete set of scale conditions can thus be found from equations (27) - (32) and (35), and this constitutes the AEDC method tested here.

\section{Results}

The evaluation of scaling methods will be based on how well scale ice shapes match the reference shapes. The quality of agreement between ice shapes is a subjective judgement. In this study, the following attributes were considered in evaluating how well scaled ice shapes matched the reference shapes: the relative quantity of ice accreted, the general shape of ice, the thickness of ice at the leading edge and (if applicable) the size and angle of horns. Differences in these characteristics between scaled and reference shapes are only significant when they exceed the run-to-run variations observed when test conditions are repeated.

Figure 3 shows results of repeatability tests for some of the conditions used in this study. Figure 3(a) represents a horn glaze ice for which repeatability was excellent. Repeatability of ice shapes in the IRT is generally very good ${ }^{12}$, but cannot always be expected to be as good as that shown. Figure 3(b) presents repeatability test results at a temperature higher than that of figure 3(a). At this condition, the ice shape and quantity were sensitive to small changes in temperature, and the irregular shape was harder to repeat than the shape of figure 3(a). 
Olsen Method The Olsen method corrects for the effect of $L W C$ on heat balance by substituting equation (17) for equation (8) to adjust the static temperature. To illustrate the ice-shape improvement this correction provides, some results for the simple rule $L W C \times$ time = constant based on equations (3) through (8) will be shown first. Ioe shapes from reference (1) at liquid-water contents of 1 and $.8 \mathrm{~g}^{3}$ are compared in figure 4 with the reference shape at $1.3 \mathrm{~g} / \mathrm{m}^{3}$. The ice is glaze for all liquid-water contents. Figure 4(a) gives ice shapes on a $5.1-\mathrm{cm}$-diameter cylinder and 4(b) on a 15.4-cm-diameter. The total accumulation appeared to remain approximately constant as $L W C$ was varied; however, because a docrease in $L W C$ decreases the release of latent heat at the leading-edge, impinging water froze faster for low liquid-water contents than for high. This effect can be seen in the decreasing horn angles in each figure as the $L W C$ was decreased.

Figure 5 shows the ice shapes which resulted from applying the Olsen method using the same test conditions as those in figure 4. Figure 5(a) gives results of tests with the 5.1-cm-diameter cylinder and $5(\mathrm{~b})$ with the $15.4-\mathrm{cm}$-diameter. Note that a temperature increase of $2.8^{\circ} \mathrm{C}$ was required to compensate for the change in $L W C$ from 1.3 to $.8 \mathrm{~g} / \mathrm{m}^{3}$. The ice shapes showed little variation over this $L W C$ range when the Olsen method was applied.

Modified French Method. Figure 6 compares results using the modified French scaling method with those from the original French method. Reference tests used a 5.1-cm-diameter cylinder and scale tests were with a $2.5-\mathrm{cm}$-diameter cylinder. The solid line represents the reference ice shape in each case. The dashed line shows the ice shape obtained when scale test conditions were established using the original French method of Charpin and Fasso ${ }^{3}$ and the dotted line, the ice shape using the modified French method as discussed above. The coordinates of the ice shapes have been adjusted to present them at a common scale for ease of comparison.

Figure 6(a) gives the results for a relatively warm glaze ice condition. In addition to scaling the size by a factor of 2 , the airspeed was scaled from $76 \mathrm{~m} / \mathrm{s}$ to $61 \mathrm{~m} / \mathrm{s}$. In view of the difficulty in repeating this ice shape (see figure 3(b)), both the French and the modified French method appeared to provide a fairly good approximation.

Figure $6(b)$ shows the results for scaling from a lower-temperature reference case than that of figure 6(a). Mixed ice resulted from this test. For this experiment, the scale airspeed was the same as the reference, $94 \mathrm{~m} / \mathrm{s}$. Distinctive horns were formed. The French method gave an ice shape (dashed line) which reproduced neither the horn size nor the ice thickness at the leading edge of the cylinder. The total quantity of scaled ice appeared to match the reference shape, however. In contrast, the modified French method gave a shape (dotted line) which closely approximated the reference ice although there is a small difference in the horn angle.

These results provide preliminary confirmation that the substitution of a laminar-flow film coefficient for the original turbulent-flow cofficient in the French analysis provided improved scaling for the conditions considered. However, for tests with high $R e$ it is possible that the original form of the French method may be more suitable.

AEDC Method The same reference conditions and size ratios were tested with the AEDC method as for the French and modified French method shown above. The results are given in figure 7.

The reference ice shape from the test results of figure $6(a)$ has been used as the reference for the AEDC method in 7(a). Again, the size was scaled from 5.1 to $2.5 \mathrm{~cm}$ and the airspeed from 76 to $61 \mathrm{~m} / \mathrm{s}$ for these tests. The scale ice shape is given by the dotted line. The scale test results matched the reference shape approximately although the relative quantity of ice accreted appeared to be somewhat less for the scaled test than for the reference. In view of the expected variability in shape shown by figure 3(b) at these conditions the AEDC method provided a reasonable guide to scaling.

Figure 7(b) presents the same reference case as figure 6(b). The resulting ice shape matched the reference shape as well as that from using the modified French method. The AEDC and modified French methods appear to have provided approximately equivalent scaling guidance for the conditions of these tests.

\section{Concluding Remarks}

This study has demonstrated the importance of correctly analyzing the leading-edge heat balance in establishing scaling methods. The Olsen method introduced a heat-balance analysis to correct temperature when the only scale test parameter which can't be matched to the reference is $L W C$. The ice shapes which resulted when the Olsen method was applied maintained both the quantity of ice and the shape when the liquid-water content was reduced from 1.3 to $.8 \mathrm{~g} / \mathrm{m}^{3}$. It was shown to give a significant improvement in scaled ice shapes over the often-applied rule LWC $x$ time $=$ constant with $t_{S}=t_{R}$

A modification of the French method in which a convective film coefficient suitable for laminar flow was substituted for the original urbulent-flow coefficient improved the ability of scaled ice shapes to reproduce reference shapes for the conditions tested. Finally, the AEDC method was tested. It also used a laminar-flow film coefficient and was shown to provide a similarly-effective method of approximating reference ice shapes.

Although the results were encouraging, all of these scaling methods need to be evaluated under a wide range of conditions and with different geometries to fully confirm their effectiveness.

\section{References}

1. Anderson, David N.: "Rime-, Mixed- and Glaze-Ice Evaluations of Three Scaling Laws," AIAA 94-0718, January, 1994.

2. Olsen, William A., unpublished notes. 
3. Charpin, Francois and Fasso, Guy, "Icing Testing in the Large Modane Wind Tumel on Full Scale and Recuced Scale Models," L'Aeronautique et l'Astronautique, no 38, 1972.

English translation published as NASA TM-75373.

4. Ruff, G.A., "Analysis and Verification of the lcing Scaling Equations," AEDC-TR-85-30, Vol 1 (Rev), March, 1986.

5. Soeder, Ronald H and Andracchio, Charles, R, NASA "Lewis Icing Research Tunnel User Manual," NASA TM 102319, June, 1990.

6. Ide, Robert F., "Liquid Water Content and Droplet Size Calibration of the NASA lewis Icing Research Tumnel," NASA TM 102447, January, 1990.

7. Messinger, B.L., "Equilibrium Temperature of an Unheated Icing Surface as a Function of Airspeed," J. Aeron. Sci. 20 No. 1, January, 1953, pp 29-42.

8. Langmuir, Irving and Blodgett, Katharine B.: "A Mathematical Investigation of Water Droplet Trajectories," Army Air Forces Technical Report No. 5418, February, 1946.

9. Tribus, Myron; Young, G.B.W.; and Boelter, L.M.K. "Analysis of Heat Transfer Over a Small Cylinder in Icing Conditions on Mount Washington," Trans ASME 70, pp 971-976, 1948.

10. Pruppacher, Hans R and Klett, James D., Microphysics of Clouds and Precipitation, Reidel, Boston, 1980.

11. Kreith, Frank, Principles of Heat Transfer, International, Scranton, 1958.

12. Shin, Jaiwon and Bond, Thomas H., "Results of an Icing Test on a NACA 0012 in the NASA Lewis Icing Research Tumnel," NASA TM-105374, AIAA 92-0647, January, 1992.

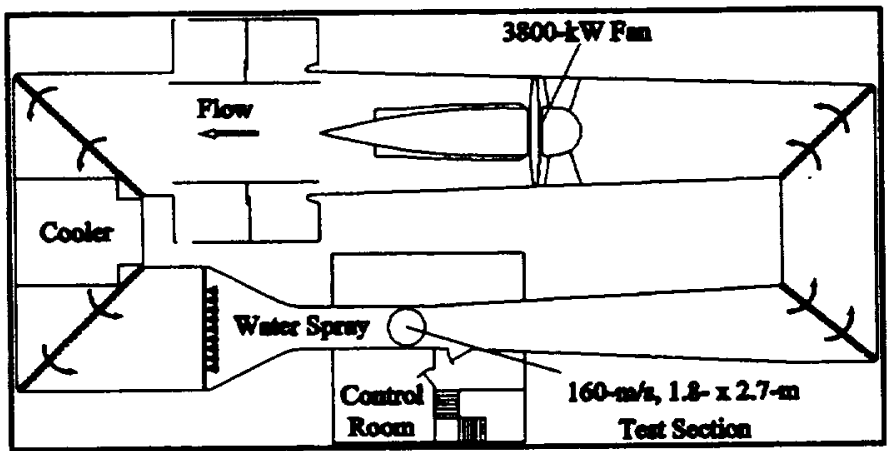

Figare 1. NASA Lewis Icing Research Tunnel (IRT).

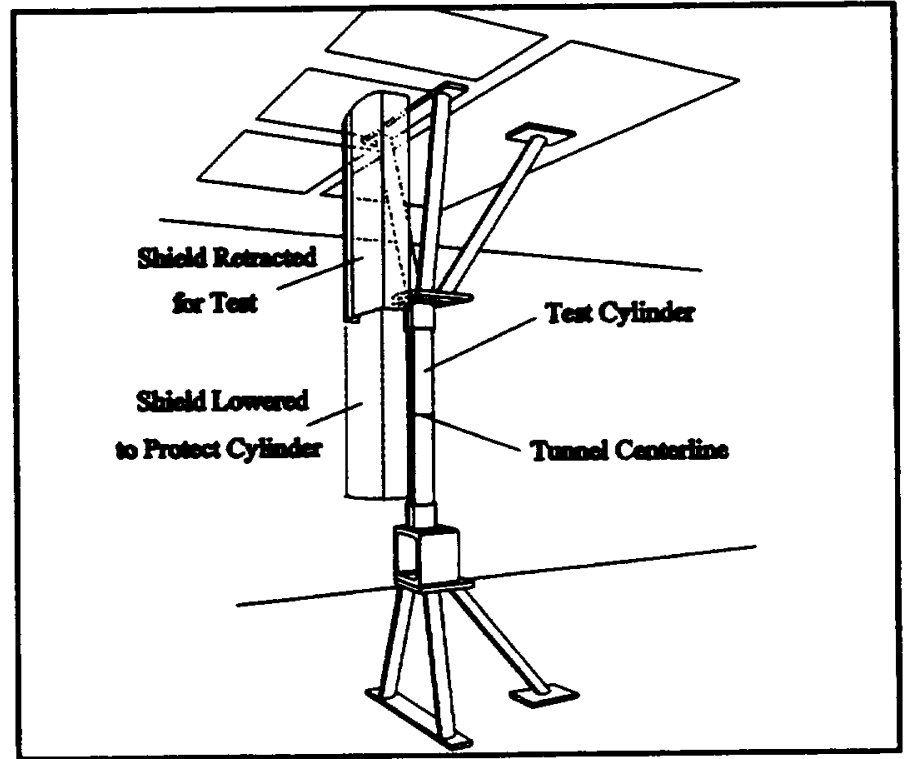

Figure 2. Test Cylinder and Shield Mounted in IRT.

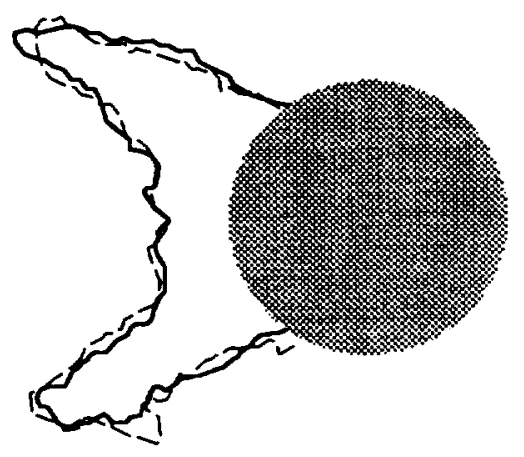

(a) $c, 5.1 \mathrm{~cm} ; V, 94 \mathrm{~m} / \mathrm{s} ; t_{\text {tor }}-7.8^{\circ} \mathrm{C} ; \delta, 30 \mu \mathrm{m} ; L W C, 1.3 \mathrm{~g} / \mathrm{m}^{3}$; $\tau, 7.8 \mathrm{~min}$.

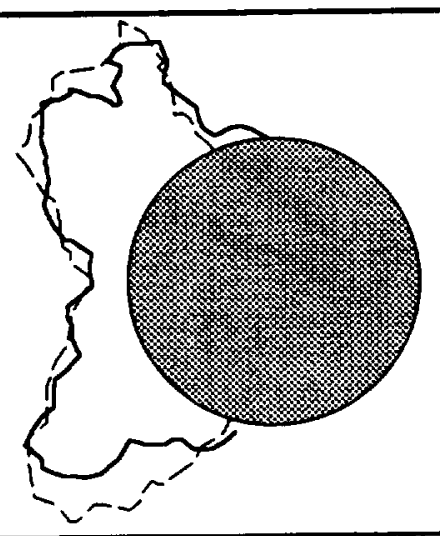

(b) $c, 5.1 \mathrm{~cm} ; V, 61 \mathrm{~m} / \mathrm{s} ; t_{\text {toos }}-2.9^{\circ} \mathrm{C} ; \delta, 20 \mu \mathrm{m} ; L W C, 1.37$ $\mathrm{g} / \mathrm{m}^{3} ; \tau, 6.6 \mathrm{~min}$

Figure 3. Comparison of Ice Shapes for Repeated Tests. 


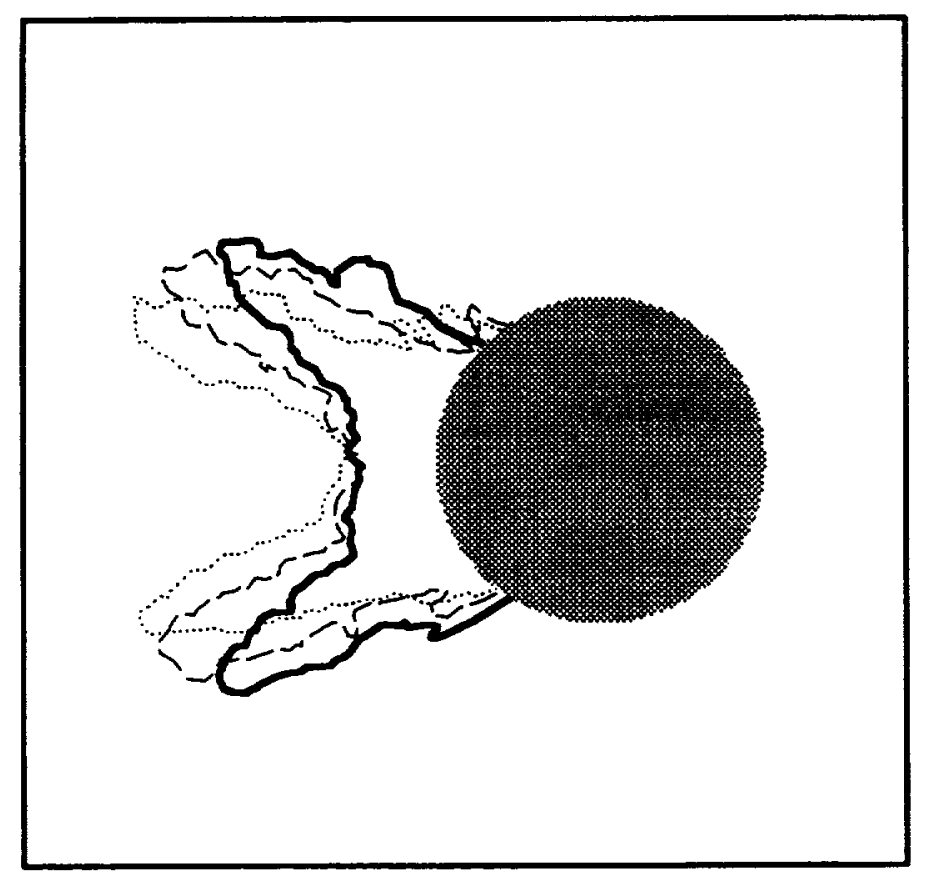

(a) Cylinder Diam, $5.1 \mathrm{~cm}(2 \mathrm{in})$.

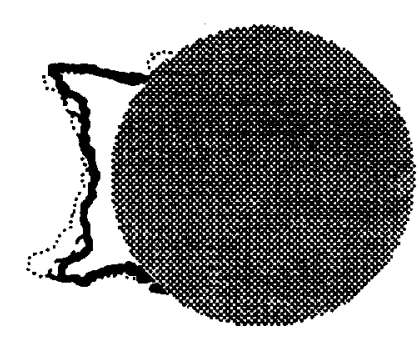

(b) Cylinder Diam, $15.6 \mathrm{~cm}$ (6 in).

Figure 4. Results of Scaling With LWC $\times$ Time = Constant. Airspeed, $94 \mathrm{~m} / \mathrm{s}(210 \mathrm{mph})$; Total Temp, $-7.8^{\circ} \mathrm{C}\left(18^{\circ} \mathrm{F}\right)$; Droplet Median Volume Diameter, $30 \mu \mathrm{m} ; L$ WC $\times$ Time, $10.15 \mathrm{~g} \mathrm{~min} / \mathrm{m}^{3}$. $L$ LTC, $1.3 \mathrm{~g} / \mathrm{m}^{3} ;$ Time, $7.8 \mathrm{~min}$

- - $L W C, 1.0 \mathrm{~g}^{3} ;$ Time, $10.1 \mathrm{~min}$

.............. LWC, $.8 \mathrm{~g}^{3} \mathrm{~m}^{3}$; Time, $12.7 \mathrm{~min}$

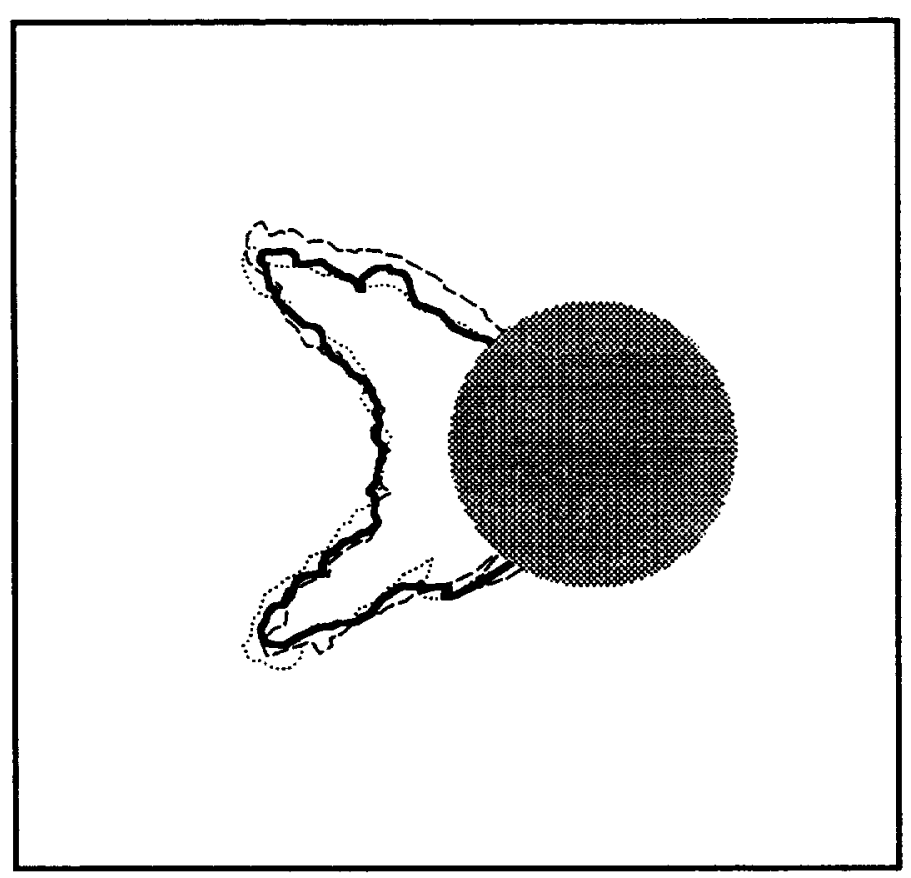

(a) Cylinder Diam., $5.1 \mathrm{~cm}(2 \mathrm{in})$.

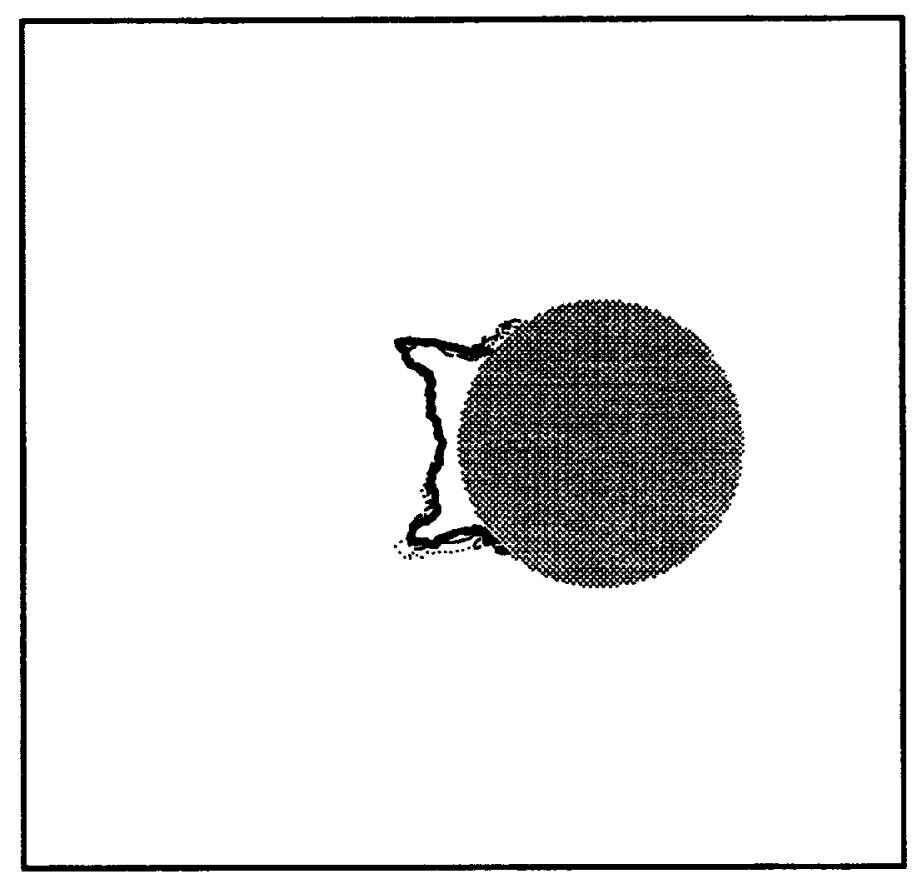

(b) Cylinder Diam., $15.6 \mathrm{~cm}$ (6 in).

Figure 5. Results for Olsen Scaling Method. Airspeed, $94 \mathrm{~m} / \mathrm{s}$ (210 mph); Droplet Median Volume Diameter, $30 \mu \mathrm{m} ; L W C \times$ Time, $10.15 \mathrm{~g} \mathrm{~min} / \mathrm{m}^{3}$.

$$
\text { LWC, } 1.3 \mathrm{~g} / \mathrm{m}^{3} \text {; Time, } 7.8 \mathrm{~min} \text {; Total Temp., }-7.8^{\circ} \mathrm{C}
$$

- - LWC, $1.0 \mathrm{~g} / \mathrm{m}^{3}$; Time, $10.1 \mathrm{~min}$; Total Temp., $-6.2^{\circ} \mathrm{C}$

.............. LWC, $.8 \mathrm{~g}^{3} \mathrm{~m}^{3}$; Time, $12.7 \mathrm{~min}$; Total Temp., $-5.0^{\circ} \mathrm{C}$ 

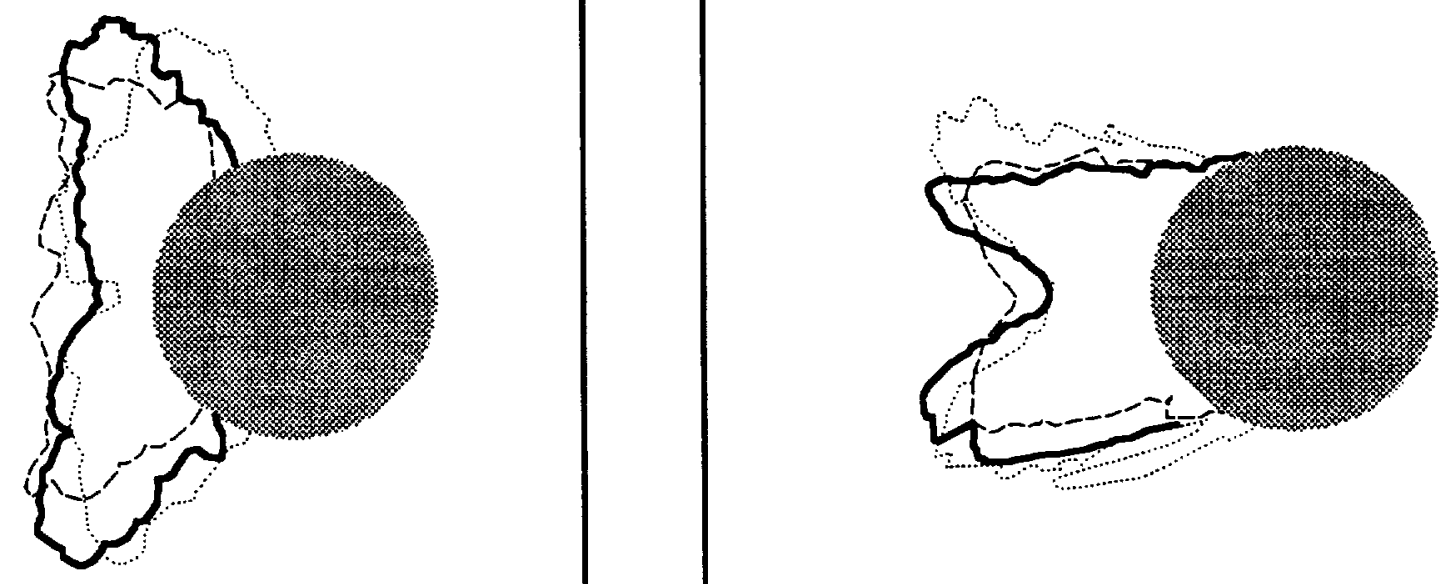

(a) $\quad c, \mathrm{~cm} \mathrm{V,m/s} t_{\text {tor }}{ }^{\circ} \mathrm{C} \delta, \mu \mathrm{m} \quad L W C, \mathrm{~g} / \mathrm{m}^{3} t, \min$

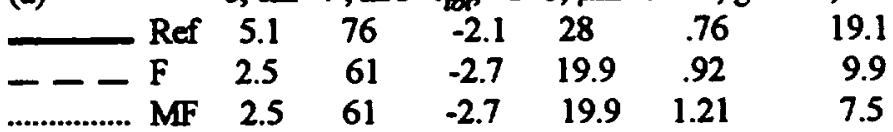

(b) $\quad c, \mathrm{~cm} V, \mathrm{~m} / \mathrm{s} t_{\text {roor }}^{\circ} \mathrm{C} \delta, \mu \mathrm{m} L W C, g / \mathrm{m}^{3} \tau, \min$

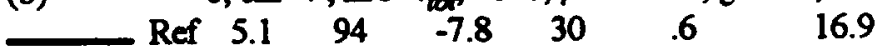
\begin{tabular}{lllllll}
\hline- F & 2.5 & 94 & -7.8 & 19.5 & .69 & 7.4
\end{tabular}

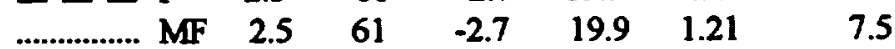

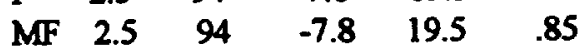
6.0

Figure 6. Comparison of French (F) and Modified French (MF) Scaling Methods.

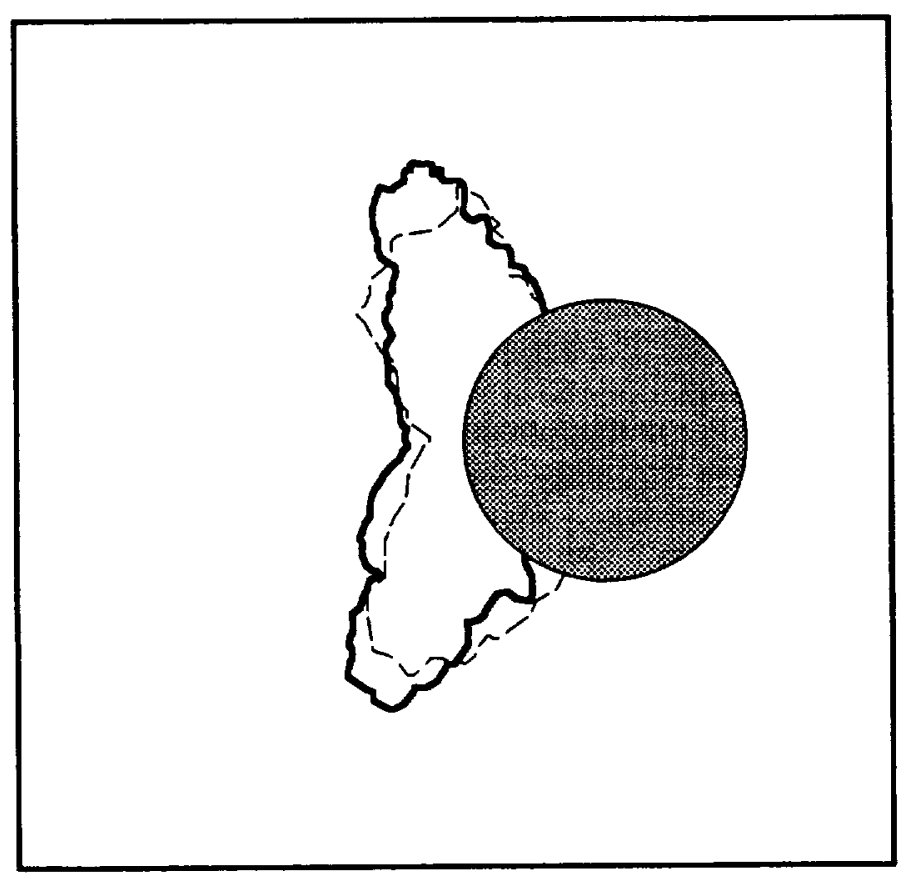

(a) $\quad c, \mathrm{~cm} V, \mathrm{~m} / \mathrm{s} t_{\text {tor }}{ }^{\circ} \mathrm{C} \delta, \mu \mathrm{m} \quad L W C, \mathrm{~g} / \mathrm{m}^{3} \tau, \min$

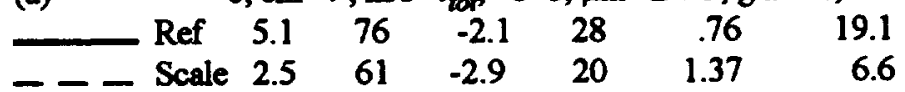

Figure 7. Results of Tests Using AEDC Scaling Method.

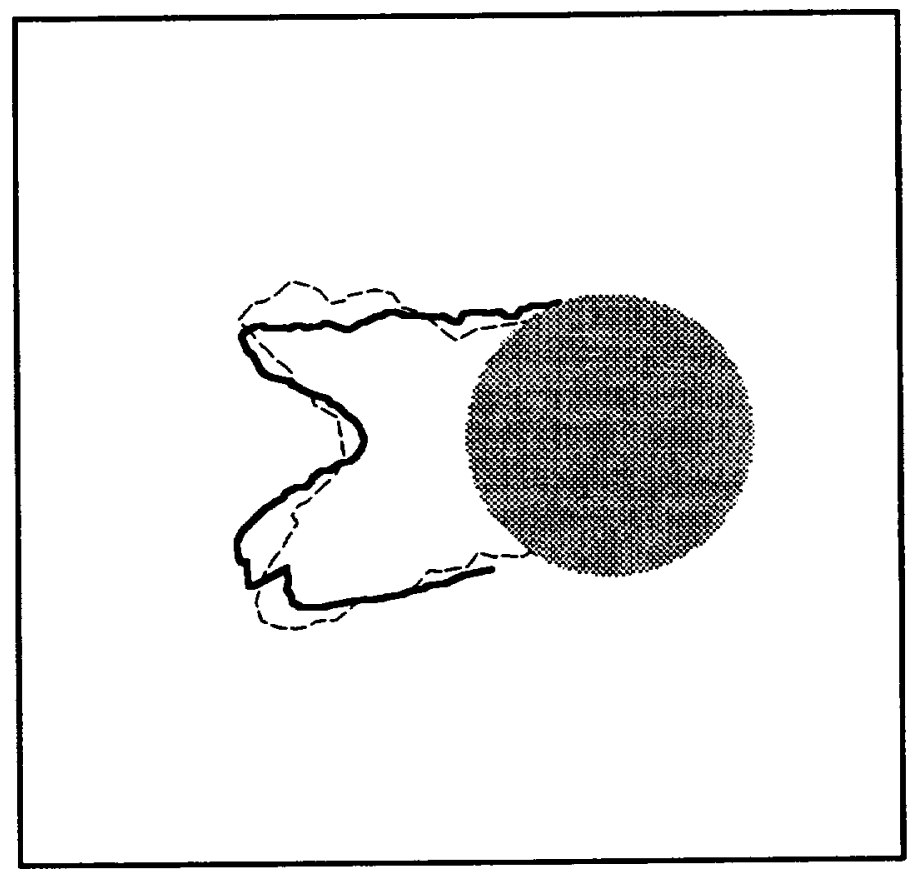

(b) $\quad c, \mathrm{~cm} V, \mathrm{~m} / \mathrm{s} t_{\operatorname{tor} 0}{ }^{\circ} \mathrm{C} \delta, \mu \mathrm{m} \quad L W C, g / \mathrm{m}^{3} \tau, \min$ $\begin{array}{lllllll}\text { Ref } & 5.1 & 94 & -7.8 & 30 & .6 & 16.9\end{array}$

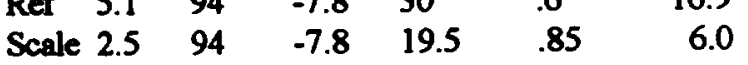




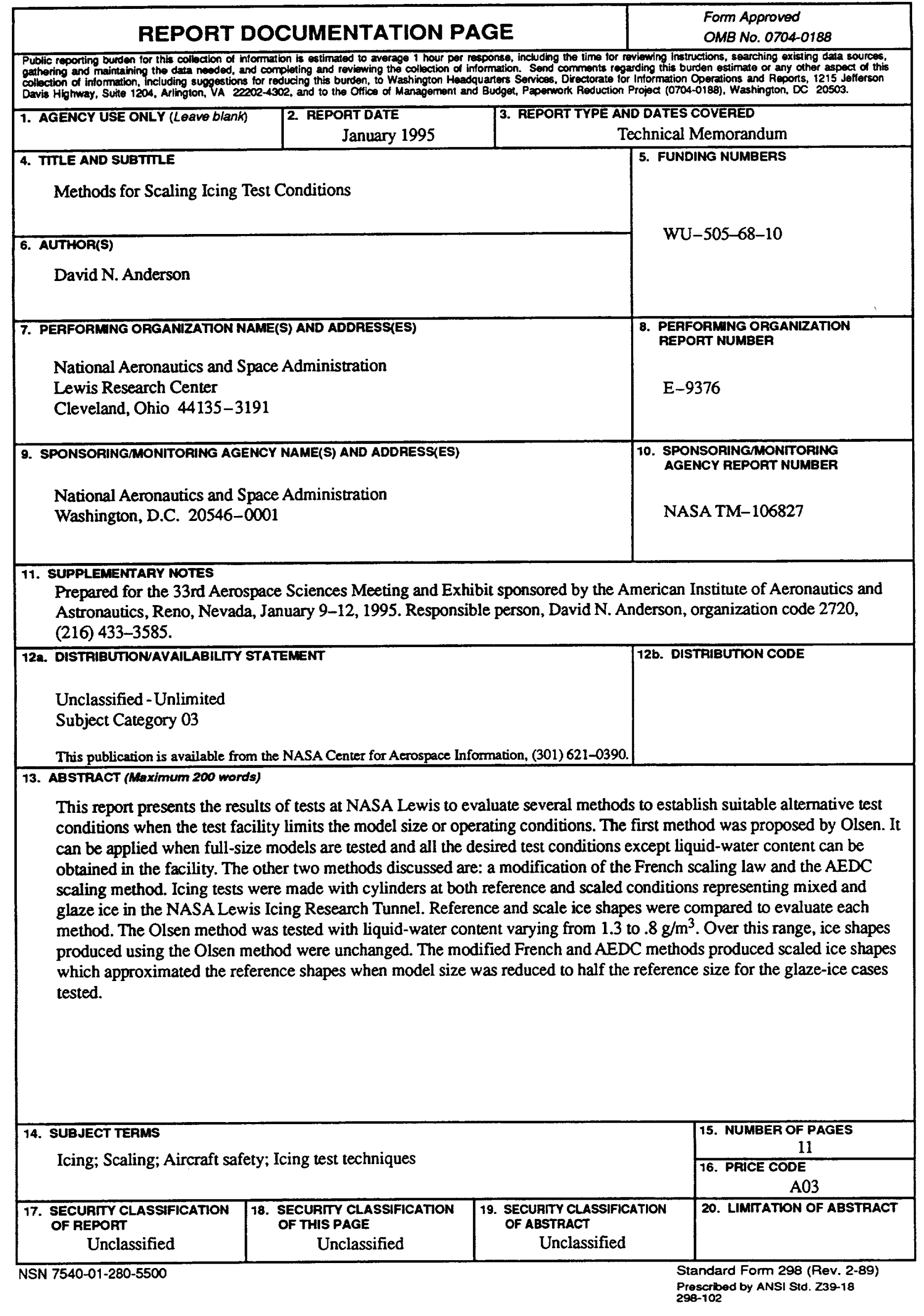

